\title{
Operating Characteristics Analysis of Rotor Systems Using MCDM Methods
}

\author{
Audrius ČEREŠKA ${ }^{1}$, Valentinas PODVEZKO ${ }^{2}$, Edmundas Kazimieras ZAVADSKAS ${ }^{*}$ \\ ${ }^{1}$ Department of Mechanical Engineering, \\ Vilnius Gediminas Technical University, \\ Basanavičiaus str. 28, 03224, Vilnius, Lithuania, \\ audrius.cereska@vgtu.lt \\ ${ }^{2}$ Department of Mathematical Statistics, \\ Vilnius Gediminas Technical University, \\ Saulètekio al. 11, 10223, Vilnius, Lithuania, \\ valentinas.podvezko@vgtu.lt. \\ ${ }^{3}$ Research Institute of Smart Building Technologies, \\ Vilnius Gediminas Technical University, \\ Saulètekio al. 11, 10223, Vilnius, Lithuania, \\ *Corresponding author: edmundas.zavadskas@vgtu.lt.
}

\begin{abstract}
The paper presents multi-criteria analysis of operating characteristics of rotor systems with tilting pad bearings. Special stand with measuring equipment was used for experimental researches. Three types of bearings were tested while changing the speed of rotor rotation and the clearance between the rotor and the bearing pad. Results of 27 measurements have been processed using multi-criteria analysis. Three methods have been used for estimating criteria weights: entropy and new methods CILOS (Criterion Impact LOS) and Objective criteria of weight determination IDOCRIW integrated (Integrated Determination of Objective Criteria Weights). For the selection of priority several well-known and widely used MCDM methods such as COPRAS, SAW and TOPSIS have been used.
\end{abstract}

Keywords: rotor system, bearing, characteristics, MCDM, objective weight, entropy method, CILOS method, IDOCRIW method.

\section{Introduction}

Hydrodynamic bearings are one of the most important components in rotary systems. They are used in various technological machines, turbo generators, turbo compressors, steam turbines, pumps, grinding machine spindles, generators, gas turbines, fans, propulsion machinery, and a number of other mechanisms, but it is designed to significantly less work for systems with hydrodynamic bearings diagnosis methods and analysis than for systems with rolling bearings $[1,2,3]$.

When the temperature of the bearing in the operating zone has reached critical values [4], the oil viscosity and the clearance between the rotor and the bearing segment are decreased. Then bearing is operating in a semi-fluid lubrication mode. As a result, operating time of rotor systems is shortened and it can cause failures. Such phenomena could disturb the work process and cause large losses.

Dynamic parameters of the system "rotor - oil bearing" and parameters of the oil taken together define the stability of the rotor system, expressed by the speed of rotor rotation.

When this rate of rotation of the rotor system is reached and exceeded, occur automatic transverse rotor vibrations, caused by turbulence in the oil bearing clearances $[5,6$, 7]. Stability may be achieved through the design of a hydrodynamic bearing using dampening elements $[8,9]$.

In order to increase stiffness of the hydrodynamic bearing and stability of rotor rotation in a wider rotation frequencies range, together with the sliding sleeve bearings were designed bearings with various structural features: sleeve, sleeve with the ring, elliptical, tilting pad, etc., etc. $[10,11]$. Hydrodynamic bearings with tilting pad demonstrated good performance on adaptation options, but in order to improve rotational stability of the rotor a variety of bearing structures with additional segments spanning elastic elements have been used. These elements are regulating distribution of the loads between pad. This ensures a uniform thickness of oil hydrodynamic film as well as 
increased stability of the rotor rotation. It also increases the stiffness of the rotor system.

Having information about the performance characteristics of the rotor system one can determine the current status of the system and to choose the most optimal variant during design process. For latter a MCDM (Multiple Criteria Decision Making) techniques can be applied, which are successfully utilized for the optimization of technical solutions in laser technologies [12] and other technical solutions $[13,14,15]$.

MCDM methods are based on decisions matrix $R=\left\|r_{i j}\right\|$, criterion statistics (experimental criterion values) and criteria weights (weights) vector $\Omega=\left(\omega_{i}\right)$, where $i=1,2, \ldots, n ; j=1,2, \ldots$, $m$ - the number of criteria; $n$ - compared the number of options [16].

For the comparison of 27 variants customized MCDM (Multiple Criteria Decision Making) methods were utilized: COPRAS (Complex Proportional Assessment) [17, 18], SAW (Simple Additive Weighting) [18-21], TOPSIS (The Technique for Order of Preference by Similarity to Ideal Solution) [19 - 21].

Subjective criteria weighting methods have been used the most in practice [19, 22-27].

Data structure can be evaluated and degree of dominance (or objective weights of criteria) of each criteria can be estimated. Objective weights compared with subjective are applied in practice much less frequently $[19,28]$. Combination weighting is based on the integration of subjective weighting and weighting objective [29-32].

Doing analysis of operating performance of rotor systems it is not possible to value the importance of the criteria for significance quantitatively, that is to estimate subjective weights of criteria. Therefore there are used effective setting methods of criteria weights in this work: entropy, criterion impact loss CILOS (Criterion Impact LOS) and aggregate objective weights IDOCRIW (Integrated Determination of Objective Criteria Weights).

\section{Research Object and Equipment}

Research object - tilting pad bearing of three types.

Bearing picture with the separate elastic strips connecting pad is given on the Figure 1.
Experimental measurements were performed using a special experimental research stand, the principal scheme of which is given on Figure 2, stand photo - on Figure 3.

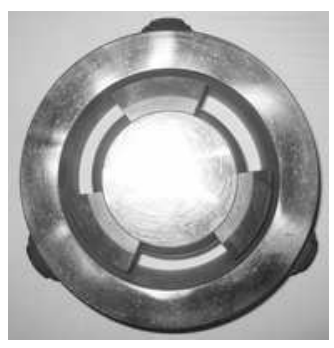

Figure 1. The tilting pad bearing picture with separate elastic strips that are connected pad

Research stand consists of: rotor system with tilting pad bearings, lubrication system of rotor system, speed control system of rotor rotation, analyses system of measurement and measurement results.

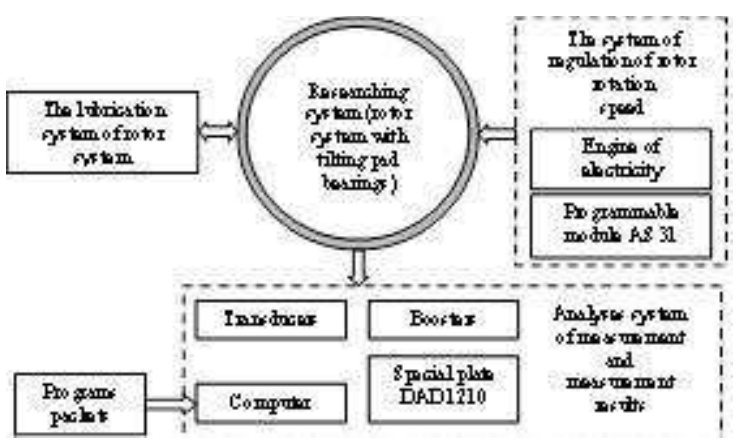

Figure 2. Principal stand scheme of researches

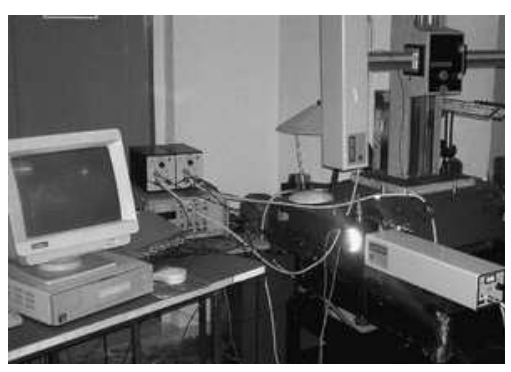

Figure 3. Stand photo of researches

The measuring system consists of: non-contact displacement measurement transducers, photoelectric phase measurement transducer, a temperature measuring transducers and pressure measuring transducers.

The rotational deviations of the rotor were measured with non-contact inductive displacement measuring transducers mod. Tr. 102 of German Company Hottinger Baldwin Messtechnik GMBH (HBM). During the measurements non-contact displacement measuring transducers arranged with $90 \square$ phase angle relative to each other on the 
bearing support and on the one cross-section plane of rotor. Positioning transducers allows measuring the position of the neck with respect to the clearance of a tilting pad bearing at any rotor rotation speed. Orientation of transducers does not have to be vertical or horizontal. It is selected suitable regarding the construction of mechanism. The temperature was measured with special temperature sensors LM 135 of SGS-THOMSON Microelectronics Company. The pressure was measured by special pressure measuring transducers.

\section{Process of Research Work and Parameters}

A principal process of implementation of experiments is presented in Figure 4. Several parameters have been varied during experiments such as the clearance between the rotor and the pad $(25,50$ and $75 \mu \mathrm{m})$, rotor's rotation speed (1000 $30005000 \mathrm{rpm})$ and the bearing type (Type 1 - tilting pad bearing without elements that are connected pad, 2 Type - tilting pad bearing with separate elastic strips that are connected pad; type 3 - tilting pad bearing with the elastic ring the is connected pad (Figure 5).

After obtaining the primary measurement data and processing it, main parameters describing the performance quality of the rotor system have been determined: eccentricities of the rotor, the orbits of the rotor axis, the pressure and temperature in the work area.

Eccentricity is the displacement of rotation axis of a rotor with respect to the geometric crosssectional axis. Planar curve of the orbit is

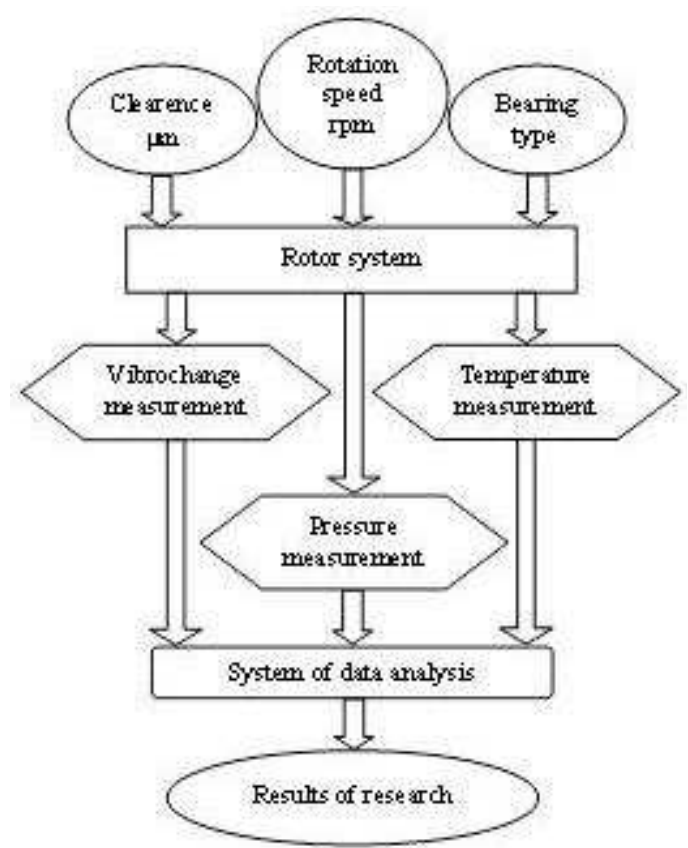

Figure 4. Principal researches scheme

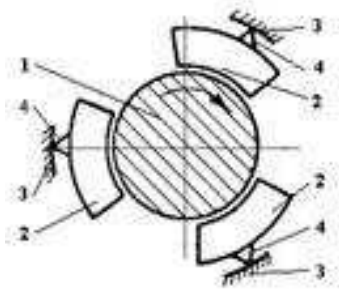

a)

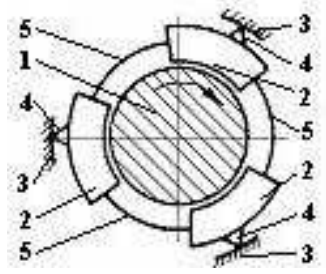

b)

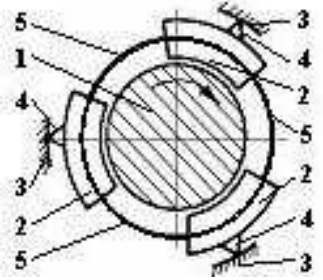

c)

Figure 5. Tilting pad bearings:

a - without elements that are connected pad ( 1 - rotor, 2 - pad, 3 - frame, 4 - adaptive support); b - with separate elastic strips that are connected pad ( 1 - rotor, 2 - pad, 3 - frame, 4 - adaptive support, 5 strips that are connected pad) $\mathrm{c}$ - with the elastic ring that are connected pad 
obtained by measuring the position of the rotating rotor surface in two perpendicular directions.

Oil pressure in the clearance between the rotor and the bearing pad is ensuring the stiffness and stability of the bearing.

Temperature of elements of lubricant and bearing is important operational characteristic, because the performance of rotor system quality depends on the elements temperature of rotor system.
Different types of tilting pad bearings principal structures are given on Figure 5 a, b, c.

All these characteristics of work are correlated with each other and when one characteristic changes the other characteristics changes too.

\section{The Application of MCDM Methods}

After the analysis of measurement data 27 data groups that are listed in Table 1 were obtained.

Table 1. Operating characteristics of rotor system

\begin{tabular}{|c|c|c|c|c|c|c|c|}
\hline Trial & $\begin{array}{c}\text { Clearance } \\
t, \mu \mathrm{m}\end{array}$ & $\begin{array}{c}\text { Rotation } \\
\text { speed } \\
n, \mathrm{rpm}\end{array}$ & $\begin{array}{c}\text { Bearing } \\
\text { type }\end{array}$ & $\begin{array}{c}\text { Eccentricity } \\
e, \mu \mathrm{m}\end{array}$ & $\begin{array}{c}\text { Orbit } \\
\text { diameter } D, \\
\mu \mathrm{m}\end{array}$ & $\begin{array}{c}\text { Change } \\
\text { of pressure } \\
P / P_{\max }\end{array}$ & $\begin{array}{c}\text { Temperature } \\
T,{ }^{\circ} \mathrm{C}\end{array}$ \\
\hline 1 & 25 & 1000 & 1 & 11,48 & 8,75 & 0,74 & 27,3 \\
\hline 2 & 50 & 1000 & 1 & 21,52 & 10,93 & 0,17 & 25,6 \\
\hline 3 & 75 & 1000 & 1 & 30,11 & 13,67 & 0,03 & 24,2 \\
\hline 4 & 25 & 1000 & 2 & 10,14 & 8,81 & 0,69 & 27,4 \\
\hline 5 & 50 & 1000 & 2 & 19,86 & 11,01 & 0,14 & 25,3 \\
\hline 6 & 75 & 1000 & 2 & 30,08 & 12,97 & 0,02 & 23,9 \\
\hline 7 & 25 & 1000 & 3 & 9,94 & 8,02 & 0,67 & 27,2 \\
\hline 8 & 50 & 1000 & 3 & 19,91 & 10,58 & 0,16 & 26,9 \\
\hline 9 & 75 & 1000 & 3 & 28,58 & 12,30 & 0,02 & 22,7 \\
\hline 10 & 25 & 3000 & 1 & 11,16 & 7,20 & 0,81 & 44,9 \\
\hline 11 & 50 & 3000 & 1 & 20,64 & 9,00 & 0,19 & 42,7 \\
\hline 12 & 75 & 3000 & 1 & 29,87 & 11,25 & 0,04 & 40,3 \\
\hline 13 & 25 & 3000 & 2 & 9,88 & 7,15 & 0,86 & 44,6 \\
\hline 14 & 50 & 3000 & 2 & 18,32 & 9,03 & 0,21 & 41,7 \\
\hline 15 & 75 & 3000 & 2 & 27,97 & 10,87 & 0,04 & 40,1 \\
\hline 16 & 25 & 3000 & 3 & 8,36 & 6,93 & 0,84 & 43,8 \\
\hline 17 & 50 & 3000 & 3 & 19,32 & 8,75 & 0,22 & 39,8 \\
\hline 18 & 75 & 3000 & 3 & 27,23 & 9,02 & 0,05 & 38,7 \\
\hline 19 & 25 & 5000 & 1 & 10,90 & 6,50 & 0,88 & 75,6 \\
\hline 20 & 50 & 5000 & 1 & 19,85 & 8,13 & 0,22 & 74,8 \\
\hline 21 & 75 & 5000 & 1 & 29,68 & 10,16 & 0,05 & 72,7 \\
\hline 22 & 25 & 5000 & 2 & 9,56 & 6,66 & 0,99 & 76,1 \\
\hline 23 & 50 & 5000 & 2 & 18,76 & 7,98 & 0,20 & 73,2 \\
\hline 24 & 75 & 5000 & 2 & 28,63 & 9,73 & 0,039 & 71,9 \\
\hline 25 & 25 & 5000 & 3 & 8,03 & 5,84 & 0,96 & 75,1 \\
\hline 26 & 50 & 5000 & 3 & 17,69 & 6,79 & 0,193 & 73,7 \\
\hline 27 & 75 & 5000 & 3 & 27,55 & 8,48 & 0,05 & 72,5 \\
\hline
\end{tabular}


Operating characteristics of rotor systems are analyzed using MCDM methods (e, D, P/Pmax and $\mathrm{T}$ ) and are determined their weights. All criteria except $\mathrm{P} / \mathrm{Pmax}$ are minimized.

\subsection{Entropy method}

Entropy method was offered by Claude E. Shannon [33]. Entropy weights are defined as follows [19]:

1. The values of criteria are normalized using equation (1):

$$
\widetilde{r}_{i j}=\frac{r_{i j}}{\sum_{i=1}^{n} r_{i j}}
$$

2. The entropy level of each criterion is calculated as follows:

$$
\begin{aligned}
E_{j}=-\frac{1}{\ln n} \sum_{i=1}^{n} \widetilde{r}_{i j} \cdot \ln \widetilde{r}_{i j}, \\
\quad\left(j=1,2, \ldots, m ; 0 \leq E_{j} \leq 1\right)
\end{aligned}
$$

3. The variation level of each criterion is calculated:

$d_{j}=1-E_{j}$

4. Entropy weights are calculated $d_{j}$ normalized values:

$$
W_{j}=\frac{d_{j}}{\sum_{j=1}^{m} d_{j}}
$$

Entropy weights reflects the structure of data, the degree of its non-homogeneity. The weight of homogeneous data (when the values of the criteria do not differ considerably), which is obtained by the entropy method (4), is about zero and does not have a strong influence on evaluation. The largest weight of the criterion obtained by using the entropy method corresponds to the criterion with the highest weight ratio.

\subsection{Method of criterion impact loss - CILOS}

It is another promising method of criteria impact loss and determination of objective weights [34]. The method is evaluating the loss of each criterion, until one of the remaining criteria is acquiring the optimum - the maximum or the minimum value. Method's algorithm, formalization, description and application has been presented by Zavadskas et al. [35]. The logic of the method of criteria impact loss, the basic ideas, stages and a calculation algorithm are executed by the procedure that is given below.

Criteria that are minimized are transformed to maximizing, according to the following equation:

$\bar{r}_{i j}=\frac{\min _{i} r_{i j}}{r_{i j}}$

New matrix is denoted as $X=\left\|x_{i j}\right\|$. The maximum values of each column (i.e. every criteria) are calculated $x_{j}=\max _{i} x_{i j}=x_{k_{j} j}$ where $k_{j} \mathrm{j}$-the lines of column with the largest number of element.

It is formed a square matrix $A=\left\|a_{i j}\right\|$ from $k_{j}=$ $\mathrm{s}$ rows values of matrix $\mathrm{X} \quad x_{k_{j} j}$ are corresponded to the j-maximum criterion: $a_{j j}=$ $x_{j}(i, j=1,2, \ldots, m ; m$ - number of criteria), that is the maximum values of all the criteria will appear in the main diagonal of the matrix.

It is made matrix $P=\left\|p_{i j}\right\|$ of the relative losses:

$$
p_{i j}=\frac{x j-a_{i j}}{x_{j}}\left(p_{i i}=0 ; i, j=1,2, \ldots, m\right)
$$

Elements $p_{i j}$ of $P$ matrix shows how is lost alternative relatively $j$-th criterion, if the $i$-th criteria is selected the best.

Weights $q=\left(q 1, q 2, \ldots, q_{m}\right)$ can find from the system:

$F q=0$.

here, matrix $F$ is as follows:

$$
F=\left|\begin{array}{cccc}
-\sum_{i=1}^{m} p_{i 1} & p_{12} & \cdots & p_{1 m} \\
p_{21} & -\sum_{i=1}^{m} p_{i 2} & & p_{2 m} \\
\cdots & & \\
p_{m 1} & p_{m 2} & \cdots & -\sum_{i=1}^{m} p_{i m}
\end{array}\right|
$$

The method based on the criterion impact loss offsets the drawback of the entropy method. Thus, when the values of a criterion do not considerably differ, the elements $p_{i j}$ of the matrix $P$ of relative loss of criterion impact (6) approach zero, while the respective criterion weight increases and has a strong impact on the evaluation. In the case of homogeneity, when the values of one of the criteria are the same in all the alternatives, all relative losses of the criterion, as well as its total loss, are equal to 
zero. Therefore, the linear system of equations (7) has no sense because one column of elements in matrix $P$ is equal to zero.

\subsection{Aggregate objective weights IDOCRIW method}

Using idea of the different impact weights to connection into a single overall weight $[19,29$ 32], it is possible to connect the entropy weights $W_{j}$ and weights $q_{j}$ of criteria impact loss methods connecting them to the common objective criteria for assessment of the structure of the array weights $\omega_{j}$ :

$$
\omega_{j}=\frac{q_{j} W_{j}}{\sum_{j=1}^{m} q_{j} W_{j}} .
$$

These weights will emphasize the separation of the particular values of criteria (entropy characteristic), but impact of these criteria is decreased, due the higher loss in other criteria.

Calculated weights of the entropy and criteria loss of impact are combined into aggregated weights and then are used in multi-criteria assessment, for ranking of options and for selection of the best alternative.

\subsection{The calculation weights of entropy, CILOS and IDOCRIW methods}

Previously described theory of weights determination was applied to the analysis of operating characteristics of rotor systems and for the comparison of options. Objective weights were calculated using three different methods - entropy, CILOS (Criterion Impact LOS) and aggregate objective weights IDOCRIW (Integrated Determination of Objective Criteria Weights).

Data are presented in Table 1.

One can prognosticate that the maximum weight of entropy will have $X_{3}$ criteria, because it's ratio of the maximum and the minimum values is the highest and is equal to 55.5.

Matrix of the loss of criteria impact is calculated using (5) - (8) equations and is:

Values of criteria impact loss method weights depend on the general criteria of loss (the main diagonals with negative elements). It can be predicted that the greatest impact on the criteria weight loss method will have the $X_{2}$ criteria, because its loss $(0.6483)$ is the smallest. Separate criteria losses with respect to other criteria have impact to criteria weights values too.

Values of entropy, of method of loss impact and are aggregated weights are given in Table 2 .

In summary, it could be argued that weights of the impact loss method are different from the entropy weights and methods are complemented each other. Summarized weights are reflecting advantages of both methods and will be applied for determine priorities of different options.

Table 2. Values of criteria weights

\begin{tabular}{|c|c|c|c|c|}
\hline Criterion & $X_{1}$ & $X_{2}$ & $X_{3}$ & $X_{4}$ \\
\hline \multicolumn{5}{|c|}{ Weights obtained by the entropy method } \\
\hline Weight & 0.1161 & 0.0329 & 0.7265 & 0.1246 \\
\hline Rank & 3 & 4 & 1 & 2 \\
\hline Weights obtained by the criterion impact loss \\
method \\
\hline Weight & 0.2123 & 0.2878 & 0.2418 & 0.2581 \\
\hline Rank & 4 & 1 & 3 & 2 \\
\hline \multicolumn{6}{|c|}{ Aggregate weights } \\
\hline Weight & 0.1019 & 0.0391 & 0.7261 & 0.1329 \\
\hline Rank & 3 & 4 & 1 & 2 \\
\hline
\end{tabular}

\subsection{Results of the evaluation}

According to the proposed model a task was solved, on purpose to gauge operating characteristics of the rotor system that are given on the Table 1.

In Table 3 presented the priorities estimated using the generalized theory of weights and different MCDM methods.

Examining data of results in Table 3, it can be noted that operating characteristics compared to the TOPSIS, COPRAS, SAW methods, the best version is 22 .

Although if the work characteristics are evaluated separately, it can see that the criteria $e$ and $D$ has the best values in 25-th version, the $T$ characteristic - 9-th version and $P / P_{\max }$ characteristic is the best variant 22 only.

Evaluating values of weights of work characteristics of rotor system it is found, that the highest aggregate weight has work characteristic $P / P_{\max }$. 
Table 3. The ranking of the states based on the theory of aggregating weights and using various MCDM methods

\begin{tabular}{|c|c|c|c|c|c|c|c|c|}
\hline Trial & TOPSIS & Rank & COPRAS & Rank & SAW & Rank & $\begin{array}{l}\text { Rank } \\
\text { mean }\end{array}$ & $\begin{array}{l}\text { Total } \\
\text { rank }\end{array}$ \\
\hline 1 & 0.7720 & 7 & 0.0741 & 7 & 0.0729 & 7 & 7 & 7 \\
\hline 2 & 0.1635 & 16 & 0.0230 & 12 & 0.0232 & 12 & 13.3 & $12-13$ \\
\hline 3 & 0.0880 & 20 & 0.0113 & $20-21$ & 0.0129 & 20 & 20.2 & 20 \\
\hline 4 & 0.7269 & 8 & 0.0712 & 8 & 0.0701 & 8 & 8 & 8 \\
\hline 5 & 0.1431 & 18 & 0.0214 & 17 & 0.0214 & 16 & 17 & $17-18$ \\
\hline 6 & 0.0873 & 21 & 0.0107 & 24 & 0.0124 & 21 & 22 & 22 \\
\hline 7 & 0.7089 & 9 & 0.0703 & 9 & 0.0690 & 9 & 9 & 9 \\
\hline 8 & 0.1560 & 17 & 0.0226 & $14-15$ & 0.0224 & 13 & 14.8 & 15 \\
\hline 9 & 0.0894 & 19 & 0.0112 & 22 & 0.0130 & 19 & 20 & 19 \\
\hline 10 & 0.8312 & 6 & 0.0760 & 6 & 0.0754 & 6 & 6 & 6 \\
\hline 11 & 0.1684 & 14 & 0.0229 & 13 & 0.0219 & 15 & 14 & 14 \\
\hline 12 & 0.652 & 24 & 0.0110 & 23 & 0.0107 & 24 & 23.7 & 24 \\
\hline 13 & 0.8754 & 3 & 0.0799 & 3 & 0.0795 & 3 & 3 & 3 \\
\hline 14 & 0.1870 & 11 & 0.0248 & 11 & 0.0237 & 11 & 11 & 11 \\
\hline 15 & 0.0660 & 23 & 0.0113 & $20-21$ & 0.0109 & 23 & 22.2 & 23 \\
\hline 16 & 0.8585 & 5 & 0.0793 & 4 & 0.0794 & 4 & 4.3 & 4 \\
\hline 17 & 0.1959 & 10 & 0.0255 & 10 & 0.0245 & 10 & 10 & 10 \\
\hline 18 & 0.0723 & 22 & 0.0124 & 19 & 0.0120 & 22 & 21 & 21 \\
\hline 19 & 0.8652 & 4 & 0.0775 & 5 & 0.0788 & 5 & 4.7 & 5 \\
\hline 20 & 0.1856 & 12 & 0.0226 & $14-15$ & 0.0223 & 14 & 13.5 & 12 \\
\hline 21 & 0.0298 & 26 & 0.0099 & 26 & 0.0094 & 26 & 26 & 26 \\
\hline 22 & 0.9107 & 1 & 0.0852 & 1 & 0.0870 & 1 & 1 & 1 \\
\hline 23 & 0.1687 & 13 & 0.0215 & 16 & 0.0212 & 17 & 15.3 & 16 \\
\hline 24 & 0.0227 & 27 & 0.0093 & 27 & 0.0088 & 27 & 27 & 27 \\
\hline 25 & 0.9069 & 2 & 0.0836 & 2 & 0.0865 & 2 & 2 & 2 \\
\hline 26 & 0.1636 & 15 & 0.0212 & 18 & 0.0211 & 18 & 17 & $17-18$ \\
\hline 27 & 0.0330 & 25 & 0.0102 & 25 & 0.0098 & 25 & 25 & 25 \\
\hline
\end{tabular}

MCDM analysis results of work characteristics of rotor system are confirming the trend that the most important is work characteristic $\mathrm{P} / \mathrm{Pmax}$.

Results of calculations are confirming the meaning and necessity of work characteristics optimization using the MCDM methods of rotor systems.

\section{Conclusions}

In order to determine criteria significance of rotor system three criteria were applied: entropy, CILOS (Criterion Impact LOS), summarized of the objective of weights IDOCRIW (Integrated Determination of Objective Criteria Weights). 
The following MCDM methods have been chosen: COPRAS, SAW and TOPSIS which are well-known and widely used in related scientific literature to determine priority of variants of the rotating system.

MCDM analysis results of work characteristics of rotating system confirm the trend that the most important change of pressure is operating characteristic $\mathrm{P} / \mathrm{P}$ max.

Results of calculations confirm the meaning and necessity of work characteristics optimization of the MCDM methods of rotating systems.

The paper presents a practical example which proved that the proposed alternative assessment model can be effectively applied to operating characteristics analysis of rotating systems.

\section{REFERENCES}

1. ALLMAIER, H., C. PRIESTNER, C. SIX, H. H. PRIEBSCH, C. FORSTNER, F. NOVOTNY-FARKAS,

Predicting

Friction Reliably and Accurately in Journal Bearings - A Systematic Validation of Simulation Results with Experimental Measurements, Tribology International, vol. 44, no 10, 2011, pp. 1151-1160.

2. BRITO, F. P., A. S. MIRANDA, J. C. P., CLARO, M. FILLON, Experimental Comparison of the Performance of Journal Bearing with a Single and Twin Axial Groove Configuration, Tribology International, vol. 54, 2012, pp. 1-8.

3. DIMOND, T., A. YOUNAN, P. ALLAIRE, A Review of Tilting Pad Bearing Theory, International Journal of Rotating Machinery, vol. 2011, 2011, pp. 23.

4. DANIEL, G. B., K. L. CAVALCA, Evaluation of the Thermal Effects in Tilting Pad Bearing, International Journal of Rotating Machinery, vol. 2013, 2013, pp. 17.

5. CHASALEVRIS, A., D. SFYRIS, Evaluation of the Finite Journal Bearing Characteristics, using the Exact Analytical Solution of the Reynolds Equation, Tribology International, vol. 57, 2013, pp. 216-234.
6. LIU, H., H. XU, P. J. ELliSON, Z. JIN, Application of Computational Fluid Dynamics and Fluid-structure Interaction Method to the Lubrication Study of a Rotor-bearing System, Tribology Letters, vol. 38(3), 2010, pp. 325-336.

7. VIGNOLO, G. G., D. O. L. BARILA, M. QUINZANI, Approximate Analytical Solution to Reynolds Equation for Finite Length Journal Bearings, Tribology International, vol. 44, issue 10), 2011, pp. 1089-1099.

8. MARCINKEVIČIUS, A. H., Automatic Regulation of Clearance in a Tilting Pad Journal Bearing, Mechanika, vol. 18, no. 2, 2012, pp. 5-9.

9. MARCINKEVIČIUS, A. H., M. JUREVIČIUS, Automatic Control of Loading Forces in a Tilting Pad Journal Bearing, Advances in Mechanical Engineering, vol. 2014, 2014, pp. 9.

10. CARBONARA, D., J. R. DUARTE, M. L. BITTENCOURT, Comparison of Journal Orbits under Hydrodynamic Lubrication Regime for Traditional and Newton-Euler Loads in Combustion Engines, Latin American Journal of Solids and Structures, vol. 6, issue 1, 2009, pp. 13-33.

11. STRZELECKI, S., L. KUŚMIERZ, G. PONIEWAŻ, Thermal Deformation of Pads in Tilting 5-pad Journal Bearing, Eksploatacja i niezawodność, vol. 38, no. 2, 2008, pp. 12-16.

12. MADIĆ, M., M. RADOVANOVIĆ, D. PETKOVIĆ, B. NEDIĆ, Multi-Criteria Analysis of Laser Cut Surface Characteristics in $\mathrm{CO} 2$ Laser Cutting of Stainless Steel, Tribology in Industry, vol. 37, no. 2, 2015, pp. 236-243.

13. CHAKRABORTY, S., E. K. ZAVADSKAS, Applications of WASPAS Method in Manufacturing Decision Making, Informatica, vol. 25, no. 1, 2014, pp. 1-20.

14. CHAKRABORTY, S., E. K. ZAVADSKAS, J. ANTUCHEVICIENE, Applications of WASPAS Method as a Multi-criteria Decision Making Tool, 
Economic Computation and Economic Cybernetics, vol. 49, no. 1, 2015, pp. 5-22.

15. RIKHTEGAR, N., N. MANSOURT, A. A. OROUMIEH, A. YAZDANI-CHAMZINI, E. K. ZAVADSKAS, S. KILDIENE, Environmental Impact Assessment based Group Decision Making Methods in Mining Projects, Economic Research ekonomska istrazivanja. vol. 27, no.1, 2014, pp. 378-392.

16. BRAUERS, W. K., R. GINEVIČIUS, A. PODVIEZKO, Development of a Methodology of Evaluation of Financial Stability of Commercial Banks, Panoeconomicus, vol. 61, no.3, 2014, pp. 349-367.

17. ZAVADSKAS, E. K., A. KAKLAUSKAS, V. ŠARKA, The New Method of MultiCriteria Complex Proportional Assessment of Projects, Technological and Economic Development of Economy, vol. 1, no. 3, 1994, pp.131-139.

18. PODVEZKO, V., The Comparative Analysis of MCDM Methods SAW and COPRAS, Inžinerinè EkonomikaEngineering Economics, vol. 22, no. 2, 2011, pp 134-146.

19. HWANG, C. L., K. YOON, Multiple Attribute Decision Making - Methods and Applications, Springer, New York, 1981.

20. PODVIEZKO, A., V. PODVEZKO, Absolute and Relative Evaluation of Socio-Economic Objects Based on Multiple Criteria Decision Making Methods, Inzinerine Ekonomika Engineering Economics, vol. 25, no. 5, 2014, pp. 522-529.

21. GINEVIČIUS, R., A. PODVIEZKO, The Evaluation of Financial Stability and Soundness of Lithuanian Banks, Ekonomska istraživanja - Economic Research, vol.26, no. 2, 2013, pp. 191-208.

22. SAATY, T. L., The Analytic Hierarchy Process: Planning, Priority Setting, Resource Allocation. New York: McGrawHill, 1980.

23. PODVEZKO, V., H. SIVILEVICIUS, The Use of AHP and Rank Correlation Methods for Determining the
Significance of the Interaction Between the Elements of a Transport System Having a Strong Influence on Traffic Safety, Transport, vol. 28, no.4, 2013, pp. 389-403.

24. KERSULIENE, V., E. K. ZAVADSKAS, Z. TURSKIS, Selection of Rational Dispute Resolution Method by Applying New Step-wise Weight Assessment Ratio Analysis (SWARA), Journal of Business Economics and Management vol.11, no. 2, 2010, pp. 243-258.

25. KRYLOVAS, A., E. K. ZAVADSKAS, N. KOSAREVA, S. DADELO, New KEMIRA Method for Determining Criteria Priority and Weights in Solving MCDM Problem, International Journal of Information Technology \& Decision Making, vol. 13, no.6, 2014, pp. 1-15.

26. YAZDANI-CHAMZINI, A., A Integrated Fuzzy Multi Criteria Group Decision Making Model for Handling Equipment Selection, Journal of Civil Engineering and Management, vol. 20, no.5, 2014, pp. 660-673.

27. HASHEMKHANI ZOLFANI, S., M. BAHRAMI, Investment Prioritizing in High Tech Industries based on SWARACOPRAS Approach, Technological and Economic Development of Economy, Vol. 20, no. 3, 2004, pp. 534-553.

28. CHENG, Q., Structure Entropy Weight Method to Confirm the Weight of Evaluating Index, Systems Engineering Theory \& Practice, vol. 30, no. 7, 2010, pp. 1225-1228.

29. USTINOVICHIUS, L., E. K. ZAVADSKAS, V. PODVEZKO, Application of a Quantitative Multiple Criteria Decision Making (MCDM-1) Approach to the Analysis of Investments in Construction, Control and Cybernetics, vol. 36, no. 1, 2007, pp. 251-268.

30. MA, J. Z., P. FAN, L. H. HUANG, A Subjective and Objective Integrated Approach to Determine Attribute Weights, European Journal of Operational Research, vol. 112, no. 2, 1999, pp. 397-404. 
31. SAAD, R., M. Z. AHMAD, M. S. ABU, M. S., JUSOH, Hamming Distance Method with Subjective and Objective Weights for Personnel Selection. The Scientific World Journal Article, ID 865495, 2014, pp. 1-9.

32. WANG, T. C., H. D. LEE, Developing a Fuzzy TOPSIS Approach Based on Subjective Weights and Objective Weights, Expert Systems with Applications, vol. 36, issue 5, 2009, pp. 8980-8985.
33. SHANNON, C. E., The Mathematical Theory of Communication, Bell System Technical Journal, vol. 27, 1948, pp. 379-423.

34. MIRKIN, B. G., Problema grupovogo vibora, Moskva, Nauka, 1974, p. 256 (Russian).

35. ZAVADSKAS, E. K., V. PODVEZKO, Integrated Determination of Objective Criteria Weights in MCDM, International Journal of Information Technology \& Decision Making, 2016, DOI:10.1142/S0219622016500036. 